\title{
The Effects of Community-Based Child Protection Mechanisms on Sexual Violence against Children in Rombo District, Tanzania
}

\author{
Michael Reuben ${ }^{1}$, Fauzia Mohamed1', Felician Mutasa ${ }^{2}$ \\ ${ }^{1}$ Department of Sociology and Social Work, The Open University of Tanzania, Dar es Salaam, Tanzania \\ ${ }^{2}$ Center for Economics and Community Economic Development, The Open University of Tanzania, Dar es Salaam, Tanzania \\ Email: ^michaelreuben15@gmail.com, fauhamed@gmail.com, felicianmutasa@yahoo.com
}

How to cite this paper: Reuben, M., Mohamed, F., \& Mutasa, F. (2022). The Effects of Community-Based Child Protection Mechanisms on Sexual Violence against Children in Rombo District, Tanzania. Open Journal of Social Sciences, 10, 57-71. https://doi.org/10.4236/jss.2022.101005

Received: October 6, 2021

Accepted: January 7, 2022

Published: January 10, 2022

Copyright ( 2022 by author(s) and Scientific Research Publishing Inc. This work is licensed under the Creative Commons Attribution International License (CC BY 4.0).

http://creativecommons.org/licenses/by/4.0/ Open Access

\begin{abstract}
This paper aimed at examining the effects of community-based child protection mechanisms on sexual violence against children in Rombo District, Tanzania. Little research has been conducted using robust methodologies to investigate the effects of community-based child protection mechanisms in Tanzania. Thus, a mixed-method study design using interviews and focus group discussions were conducted to collect data on the effects of community-based child protection mechanisms in Rombo District in Kilimanjaro region. The region has been implementing community-based child protection mechanisms interventions to end sexual violence against children. One hundred and fifty-eight (158) participants were involved in the study. A hundred and eight (108) respondents participated in a survey, forty participated in focus group discussions and ten participated in interviews. Data were analysed quantitatively using Statistical Package for Social Sciences version 23 and qualitatively using thematic categories to facilitate interpretation. The study finding indicated that Community-based Child Protection Mechanisms have a contribution towards ending sexual violence against children. The interventions have made parents more vigilant, willing and ready to report sexual violence against children to community-based child protection mechanisms, have improved access to services on sexual violence against children, have increased proper handling of cases reported to community-based child protection mechanisms and have improved reporting of sexual violence against children cases to the Police and Social Welfare Officers. Furthermore, the interventions have improved case management and have strengthened collaboration between actors in Rombo District. However, lack of funds and inade-
\end{abstract}


quate knowledge and skills have constrained the implementation of community-based child protection mechanisms interventions in Rombo District. Therefore, the study recommends that the government and Civil Society Organizations should invest in community-based child protection mechanisms in terms of the provision of financial resources and skills development in order to combat sexual violence against children.

\section{Keywords}

Community-Based Child Protection Mechanisms, Sexual Violence, Rombo, Tanzania

\section{Introduction}

Sexual Violence Against children is one of the largest silent global pandemics, comprising sexual abuse and rape affecting all children below the age of 18 years (Ligiero et al., 2019). To combat sexual violence against children, Tanzania has established Community-based Child Protection Mechanisms (CBCPMs) such as women and child protection committees across Tanzania as per the National Plan of Action to Eliminate Violence against Women and Children (NPA VAWC 2017/2018-2021/2022).

The CBCPMs are fundamental elements of the child protection system, the network or group of individuals to protect children against exploitation, abuse, violence and neglect (Wessells et al., 2014). The involvement of the community in social work is the agenda that is gaining importance in the debate on child protection in social work. According to Fazzi (2019), the effective measures of promoting child well-being must be included in both formal and informal broader systems.

Globally, the evolution of CBCPMs dates back to the 1990s and 2000s, when many works of international agencies on child protection solely focused on child labour, child trafficking, street children and sexual exploitation. Although children were supported through these interventions, evidence indicates that these interventions were fragmented and did not have much effect on the protection of children against abuse.

According to literature, the existing child protection interventions in China mainly emphasize family, school, social and judicial protection and ignore the community as an important environment for children to grow up. The current study proposes the establishment of community-based child protection systems to build a friendly environment for children. The approach used in a study in China is different from the approach used in the current study where the emphasis is on networking and collaboration of different actors and stakeholders at school, family, community and government levels ( $\mathrm{Wu}, 2020)$. The study also found that community-based mechanisms were established in Lebanon to engender hope among children (O’Leary et al., 2015). 
Previous studies revealed that cultural practices and poverty increase the vulnerability of children to defilement. Furthermore, the role of the CBCPMs was considered as protection of children against defilement, follow-up of cases, conducting referrals of victims to the support services, and ensuring that children grow up in a stable environment (Ireri, 2018). For example, family disharmony, religious values, uncomfortable environment, technology and internet and lack of education were reported as among the reasons behind the phenomenon of sexual violence against children in Nanggroe Aceh Darussalam and West Java Provinces in Indonesia.

In another study in Nigeria, unemployment, financial difficulties, unfavourable culture and traditions were found to have increased the rate of violence against children (Collins, 2020). Ezekiel et al. (2017) in a study on child abuse in Tanzania cited poverty, ambitions and moral degradation, myths and beliefs, urbanization, foreign culture and poor parental care as causes of child sexual abuse in the country. The study revealed further that in Tanzania, all forms of violence including sexual violence tend to be high in low and middle-income countries compared to high-income countries (Cerna-Turoff et al., 2021).

The CBCPMs in Ethiopia, Uganda and the Democratic Republic of Congo were established to prevent violence against refugees' children, to identify children and reintegrate them back to school, assist referrals of rape cases and improve reporting (War Child, UK, 2010; Prickett, 2013; Child Protection Working Group, 2012; Plan International, 2015). Moreover, CBCPMs in Kisii and Kilifi Kenya were established to combat sexual violence against teenage boys by older women (Wessells, 2014). These study findings indicate that a community-led approach to child protection was effective in reducing sexual abuse and exploitation of girls. In another study, Chilwalo (2020) studied community-based mechanisms focusing on sexual abuse, early pregnancy and child marriage against children in Zambia. Kostelny et al. (2020) investigated the community action in ending early sex in Kilifi County in the Coast Province in Kenya.

The scale of sexual violence in Tanzania is high, whereby nearly 3 in 10 -females and approximately one in 7 males in Tanzania experience sexual violence from the age of 18 years (UNICEF Tanzania et al., 2011). However, the problem has not been thoroughly addressed. Addressing sexual violence against children is a challenging undertaking arising from the fact that these abuses are secretive, involving a range of survivors and perpetrators. Sexual violence against children is considered the biggest threat to children's rights (LHRC, 2018, 2020) and whose scale was 2365 (2018). In Tanzania, neither the community nor health or legal institutions are adequately prepared to handle child abuse cases (Kisanga, 2012).

Currently, Tanzania has developed the National Plan of Action to respond to Violence against Women and Children (NPA-VAWC 2017/2018-2021/2022) to reflect a strategic shift in thinking about addressing the problem of violence against women and children. Instead of focusing on interventions, Tanzania is now focusing on building systems that prevent violence against both women and 
children. The country requires not only a high level of coordination and cooperation among the relevant players, but also taking concrete steps toward building public and private spheres and reaching communities, families, and children (URT, 2016). As a result of NPA VAWC, CBCPMs have been established in different district councils of Tanzania, including Rombo where this study was carried out following government decisions of combining both women and children in one comprehensive plan of action.

Studies on the effects of CBCPMs have been carried out in some countries in Asia and Africa. However, little has been done using robust methodologies in different countries including Tanzania (Kostelny et al., 2020: p. 3). Therefore, this study examined the effects of CBCPMs in combating sexual violence against children in Tanzania using robust methodologies.

\section{Methodology}

\subsection{Study Design and Settings}

This study used a mixed-method approach to collect data concurrently from different perspectives of the study participants for triangulation purposes (Creswell, 2009). The study was conducted in Rombo District where the CBCPMs were implementing the interventions of ending sexual violence against children

\subsection{Study Site Selection and Recruitment of Participants}

The study was conducted in 10 wards of Rombo District in Tanzania because of a high prevalence of child sexual violence in the study area (LHRC, 2018). Furthermore, Rombo was one of the districts where the government established CBCPMs (Reuben et al., 2021). The study participants were selected using simple random and purposive sampling techniques.

\subsection{Data Collection Techniques}

Data were collected using interviews with Key Informants (KIIs), Focus Group Discussions (FGDs) and documentary reviews. Interviews and FGDs enabled the researcher to collect detailed information on the effects of CBCPMs on sexual violence against children. The interview guide and questionnaire were developed after reviewing literature of different reports and articles related to the study. Content validity was performed by ensuring that the questionnaire is checked by other experts to advice for improvement. Then, Pilot study was conducted to test validity of the instruments and triangulation was used to check consistency of findings obtained from multiple methods of data collection to ensure reliability.

Focus Group Discussions were conducted with members of CBCPMs particularly the women and child protection committee who participated in the implementation of the interventions to end sexual violence against children. In total, 4 FGDs were conducted during the study with an average of 10 participants in each FGD (Reuben et al., 2021). The discussions allowed the participants to share their experiences on their participating in the interventions. On average, 
the FGDs lasted for about 45 minutes to 1 hour. The FGDs were conducted up to the saturation point, meaning at the point where no new information was emerging.

Equally, data were collected from documentary reviews and interviews to complement information obtained from FGDs. The reviewed documents included NPA VAWC 2017/2018-2021/2022).

This study questions required the respondents to agree or disagree with the following statements:

1) The CBCPMs have galvanized community efforts on SVAC;

2) The CBCPMs have changed social norms on SVAC;

3) The CBCPMs have created sustainable child protection services;

4) Parents have become vigilant and report SVAC incidents to CBCPMs;

5) The CBCPMs have improved access to services on SVAC;

6) The CBCPMs have improved handling of cases;

7) The work of CBCPMs has improved reporting of cases to Social Wel-fare due to CBCPMs interventions;

8) The work of CBCPMs has improved reporting of SVAC to Police;

9) The CBCPMs have improved management of SVAC cases;

10)The CBCPMs have Strengthened collaboration among child protect-tion actors against SVAC.

\subsection{Data Analysis}

The data set from the qualitative and quantitative approaches were analysed separately and merged. Quantitative data were analysed using Statistical Package for Social Scientists (SPSS) version 23 to produce descriptive results through frequency and percentages. Qualitative data were analysed through content analysis by reading and analysing the narratives.

\subsection{Ethical Consideration}

The study obtained research clearance from the Open University of Tanzania (OUT), and the permission for carrying out the study in the study area was obtained from Rombo District Council and the respective wards. Participants' informed consent was obtained after explaining to them the objectives of the study and of their freedom of participating or opting out of the study unconditionally if they found it uncomfortable to continue participating in the study process. Some participants did not want a commitment to signing the consent form as they found it intimidating. To avoid unequal treatment, all study participants were allowed not to sign the consent forms. Participants' identity was not disclosed to maintain anonymity, this also included concealing information provided.

\section{Results and Discussion}

The current study investigated the CBCPMs particularly, women and child protection committees in Rombo District. This chapter presents the study findings in the subsequent sections below (Table 1). 
Table 1. The effects of CBCPMs on SVAC.

\begin{tabular}{|c|c|c|}
\hline Variables & $\mathrm{n}$ & Percent of Cases \\
\hline Galvanizing the community efforts against SVAC & 88 & 84.6 \\
\hline CBCPM's interventions on cultural norms towards SVAC & 73 & 70.2 \\
\hline Creation of sustainable services to SVAC & 67 & 64.4 \\
\hline Increased vigilance among parents and reporting of SVAC to CBCPMS & 65 & 62.5 \\
\hline Improving access to SVAC services among the beneficiaries & 64 & 61.5 \\
\hline Handling of cases reported to CBCPMS & 55 & 52.9 \\
\hline Improved reporting of SVAC cases to the Police due to CBCPMS interventions & 21 & 20.2 \\
\hline Improved reporting of SVAC cases to Social Welfare due to CBCPMS interventions & 18 & 17.3 \\
\hline Management of SVAC Cases & 50 & 46.3 \\
\hline Strengthening collaboration among child protection actors against SVAC & 60 & 55.6 \\
\hline
\end{tabular}

\subsection{The Effects of Community-based Child Protection Mechanisms on Sexual Violence against Children CBCPMs)}

\subsubsection{Galvanizing the Community Efforts against SVAC}

The respondents were asked whether CBCPMs have galvanized community efforts in preventing SVAC. Overall, most 84.6 percent of the respondents agreed that the CBCPMs have galvanized community efforts to prevent sexual violence against children in the study area. According to the participants of the FGDs and interview sessions, the community has become aware and has changed its behaviour toward protecting children. The community members are motivated to fulfil their responsibilities including taking shared responsibilities of protecting children at family and community levels. For example, in schools, the relationship between teachers and parents has improved, and some parents and community members are at the forefront in preventing sexual violence. Similarly, more community members have been reporting cases to police than was the case in the past, before the establishment of the CBCPMs. One interviewee noted:

Since the establishment of these mechanisms of fighting against sexual violence against children, we have started to see the majority of community members joining us in the campaign to protect our children (Interview, Male, Rombo).

This finding is in line with the finding in a study by Plan International (2017) revealing that community-based child protection mechanisms have spurred community efforts of preventing SVA. It was further revealed that in a Sudanese camp in Ethiopia, Child Protection Committees (CPCs) have increased awareness of child protection risks and this had positive impacts on addressing sexual violence against children. In addition, awareness has enabled community members to seek child protection support and guidance from CBCPMs. In Uganda and Zambia, the CBCPMs have strengthened community efforts of ending SVAC (War Child, UK, 2010; Stark et al., 2013). 


\subsubsection{CBCPM's Interventions on Cultural Norms towards SVAC}

About 70.2 percent of the respondents admitted that CBCPM interventions have had a positive impact on social norms. According to the findings from the questionnaire, CBCPM members agreed that their interventions have contributed to the change of behaviour among parents on the use of MASALE and culture of silence on cases related to sexual violence. "Masale" refers to the leaves, which are used by the family of the perpetrator to ask for forgiveness from the family of the victims of SVAC. A similar view was raised during FGD sessions, which confirmed that the strategies used to combat SVAC have changed social behaviours. In addition, CBCPMs have reduced the culture of silence which prevented parents from talking to their children about sexuality because of shame and the belief that such practices would encourage their children to be involved in sexual relationships.

Similar findings are reported in a study by Chilwalo (2020) in Zambia who found that CBCPMs addressed traditional values, beliefs and cultural practices that put children at the risk of all forms of violence including sexual violence. Therefore, the CBCPMs became relevant in this context. Furthermore, the findings in a study by Kostelny (2020) were consistent with the findings in a current study because of the reduction and shifting in peer pressure toward delaying sex and successful influencing the chief to ban disco matanga (a locally organized disco played at night) in Mombasa. The study revealed further that beliefs, attitudes and norms influenced children's behaviour.

\subsubsection{Creation of Sustainable Services to SVAC}

During the interviews, 64.4 percent of the participants indicated that the spread of CBCPMs members to different locations across the study area has led to sustainable child protection services. Interview participants revealed further that the cooperation between government employees and community members from different wards and villages has led to the sustainability of the fight against sexual violence.

In this regard one interview participant said, Most of us are government employees who are automatically fulfilling part of our responsibility, and we are sure that these services will continue (Interview, Female, Rombo).

Multi-sectoral collaboration between CBCPMs and other child protection actors has led to sustainable child protection services in the study area. Social Network Theory suggests that in the network perspectives, the relationship between actors or nodes was central for addressing sexual violence against children and for sustainability (Borgatti \& Ofem, 2010). This theory implies that a healthy relationship between CBCPMs and other actors influences the sustainability of child protection services. This study also revealed that for child protection services to be sustainable, the committee members should be from the same community, there should be active collaboration between CBCPMs the community, and other child protection service providers and with government officials being members in the committee. 
Community-based child protection mechanisms are the cornerstones of augmenting prevention efforts, and that collective planning among actors on behalf of vulnerable children creates a high sense of ownership and sustainable support among children (Wessells, 2016). Despite the achievements recorded by CBCPMs in terms of ensuring sustainable child protection services, this study identified some challenges affecting sustainable support such as a lack of resources (especially finances) to support these interventions, inadequate skills on sexual violence and child protection and the unequal power relationship between government officials and representatives of the marginalized groups such as disabled in terms of access to information and inability to raise voice to question some of the decisions.

\subsubsection{Increased Vigilance among Parents to Report SVAC to CBCPMS}

According to study findings from FGD, CBCPM interventions have made parents motivated and willing to educate their children. There is increased sharing of information on SVAC issues and parents collaborate with CBCPMs on sexual violence response and prevention. The findings were supported by 62.5 percent who admitted CBCPMs' interventions have parents vigilant and ready to report cases on sexual violence against children to CBCPMs. According to the ecological theory, a family is a microsystem where a child is directly involved and has a responsibility of providing care and protection (Bronfenbrenner, 1978). It is also evident that parents have the responsibility of caring for and protecting children from different forms of abuse, including sexual abuse, as reflected in the Law of Child (URT, 2009). As suggested in social work, the family has the responsibility of regulating the sexual behaviour of children and that, certain unwritten rules and norms forbid certain ways of sexual behaviour (Eneh et al., 2018).

The finding indicates further that, CBCPM interventions have encouraged parents to take action to protect their children. This finding is in line with the finding in a study by Save the Children Norway (2012) revealing that in Cambodia the village safety net program recorded numerous cases of sexual violence reported by parents. Similarly, in Rwanda evidence suggests that the main source of protection from and response to child protection was the child's immediate family, specifically parents. In all these cases, it was the children's parents who first counselled and provided immediate support. Parents also educate their daughters on SVAC (Prickett et al., 2013; Kostelny et al., 2014).

\subsubsection{Improving Access to SVAC Services among the Beneficiaries}

Regarding access to services, 61.5 percent of the respondents were of the view that CBCPMs have improved access to child protection services on sexual violence against children. The findings from FGDs and interviews indicated that the committees' work has generated rewarding results. Currently, children, parents and community members can access the services at village, ward and district levels due to CBCPMs interventions. In addition, the findings indicate further that $\mathrm{CBCPMs}$ have recruited members from different categories including 
schools (children and teachers), the government including Village Executive Officers Ward Executive Officers, Ward Executive Coordinators, Community Development Officers, women economic groups and representatives of the marginalized groups to provide child protection services against SVAC (NPA VAWC). Such arrangement has improved the provision of referral support, mentorship to parents and counselling services to the victims of sexual violence. The findings from interviews and FGDs in Rombo indicate that different mechanisms have been established in different wards to increase access to supportive services. For example, JITAMBUE clubs have been established in primary and secondary schools as a forum for children to discuss issues on sexual abuse and the measures to be taken to combat the problem. This distribution of committee members according to their location and their combination has increased access to services and support. Furthermore, committee members reported to have been using mobile phones as a tool of reporting SVAC to the relevant organs, the numbers to call are given to community members to enable make emergency calls at any time to report any SVAC incidence that will come into their attention.

\subsubsection{Handling of Cases Reported to CBCPMS}

Handling of cases has been an iconic feature for CBCPMs work, as supported by 52.9 percent of the respondents that cases on sexual violence against children were handled properly. The findings from FGD on the handling of sexual violence against children indicate that once CBCPMs receive cases of sexual violence they immediately report it to the Police Department. The findings indicate further that extended that CBCPMs do not have the mandate of investigating cases on sexual violence because the Tanzania Law of the Child provides that all cases should be reported to the Police and Social Welfare Department. The Law of the Child Act requires that all cases of sexual violence be reported to the relevant authorities (URT, 2009). The findings of the current study revealed that CBCPMs have worked in line with the laws by ensuring that all concerns are received and reported immediately to the Police and Social Welfare. The study findings revealed further that, sexual violence cases that were reported to СВСPMS members were referred to the relevant authorities in time. This finding is consistent with what is stipulated in the Tanzania child protection regulations requiring all cases which are reported to Ward Office to be reported to the relevant authorities such as Social Welfare and the Police within 24 hours (URT, 2015).

\subsubsection{Improved Reporting of SVAC Cases to the Police Due to CBCPMS Interventions}

Reporting of SVAC cases to the Police by community members is of paramount importance and is the fulfilment of the requirement of the Law of the Child Act of 2009. It also confirms that CBCPMs have had an impact in addressing sexual violence. The findings from FGDs indicate further that, the establishment and interventions of CBCPMS have increased awareness and as a result have in- 
creased the number of reported cases to the Police. For example, many communities in the study area, in collaboration with СВCPMs have established a secret mechanism whereby any member of the community can report an incidence through a phone call.

In all 10 surveyed wards, the respondents reported having been referring cases of sexual violence to the Police Station in Rombo. According to FGDs participants, all cases from the Police Stations are reported to the Police Gender and Children Desk (PGCD) at the district level. However, the FGDs participants believe that corruption is likely to comprise the Police efforts of handling cases. A similar experience is reported in Kenya, where perpetrators of crimes such as rape and child children are often not prosecuted even after the availability of strong evidence against because of bribing the police leading to case dismissals. Thus, bribes discourage community members from reporting similar cases to the Police (Wessells et al., 2014). Similar studies in Asian countries the prevalence of high levels of corruption among members of the Police force and the Ministry of Justice Officials exacerbating the problem of abuse and sexual violence among children (Plan International, 2016).

\subsubsection{Improved Reporting of SVAC Cases to Social Welfare Due to CBCPMS Interventions}

Improved reporting was ranked low among all the aspects studied. Only 17.3 percent agreed that cases were reported to the Social Welfare due to CBCPM interventions. The study findings show that few respondents agreed with the statement. During the FGDs, participants reported not to report SVAC cases to social welfare officials because they are not available at the ward level as opposed to the police.

This study revealed that because of CBCPM's interventions, some cases have been reported to the Social Welfare Officers. However, factors affecting the reporting of SVAC cases to the department include a lack of Social Welfare Officers at the ward level, long distances from the wards to the district headquarters and lack of knowledge among the community members on social welfare services. This view was supported by committee members during FGDs in Rombo and by key informants during the interview. However, there are still some challenges in reporting SVAC cases to the relevant authorities. A report by Together for Girls (2018) suggests that, although Tanzania has substantially scaled up the number and capacity of Social Welfare Officers and Social Workers over the past decade, their number and training have still been insufficient and thereby undermining the ability of the protection systems to function properly as alluded here.

\subsubsection{Improved Management of SVAC Cases}

Improved management of sexual violence cases against children was also identified in the study. According to the study findings, about 46.3 of the respondents agreed that CBCPMs have improved case management. The FGD and interview participants reported further that, $\mathrm{CBCPMs}$ have improved identification of 
children at risk or sexually abused children, assessing them and later giving them referrals to the relevant authorities. As stated earlier, case management is done in collaboration with Social Welfare and the Police. Despite this achievement, $\mathrm{CBCPMs}$ experience some challenges in ensuring that management of cases is improved; these include lack of financial resources and transport to attend to the victims or to make follow-up cases at the police station.

In this study, improved case management has had a positive impact on combating sexual violence against children. Similarly, FGDs participants attributed the smooth management of cases to the establishment of CBCPMs. Case management follows a cycle of steps from the identification of the child's needs for protection to case closure. However, a cycle is not uniform for all children and it is not a linear process (Development Links Consult, 2016). According to one of the key informants, the CBCPMs establishment has supported the processes of case management; for example, in the past, there was a frequent breakdown of the process but now things have stabilised and children are facilitated to access the services systematically and in line with their responsibilities. The findings of the current study are in contrast with the findings in a study by Gwanyemba et al. (2016) who revealed that in one of the communities in Tanzania, the CBCPMs did not comply with the requirements of case management. For example, VEOs had the powers of deciding on the judgement of the case or even of deciding whether proceed with the case or otherwise without giving any grounds for such decisions. In most cases, these VEOs were making such decisions on child abuse cases without due consideration of the provisions of the laws, regulations or best interests of the child.

\subsubsection{Strengthened Collaboration among Child Protection Actors against SVAC}

The CBCPMs has strengthened collaboration among child protection actors and have created a bridge with other child protection actors. Among 108 respondents, 55.6 percent agreed that the mechanisms have strengthened collaboration. The FGDs participants attributed improved linkages between the Police, Social Welfare and other child protection actors in the delivery of services to the CBCPM's work. For example, the Police have been conducting investigating cases, apprehending perpetrators and enforcing the laws. The Health Department has been instrumental for health checks in cases involving sexual abuse and or violence, and Social Welfare has been supportive in counselling the victims and supporting case management. One key informant reported that linkage and collaboration have created a sense of ownership among child protection actors.

Thus, CBCPM interventions have had a significant impact on strengthening collaboration among child protection actors. As Gillieatt (2015) suggest, Social Network Theory in Social Work improves seamless service delivery, a continuum of care and care coordination. This finding concurs with the finding in a study by Wessells (2015) who revealed that СBCPMs had a high level of ownership and a collective sense that ensured responsibilities and motivations of 
working on sexual violence. Similarly, ICPREC (2012) reports that in Asia, CBCPMs linked with other actors at different levels to improve referrals at statutory bodies at a high level and improve child protection cases.

\section{Conclusion and Recommendation}

The study has revealed that $\mathrm{CBCPMs}$ have an impact at the family, community and intersection levels with other actors. Accordingly, CBCPMs have made parents more vigilant and ready to report SVAC cases, have galvanized community efforts to prevent SVAC, have created a supportive environment, have led to proper handling of cases, and have made referrals of sexual violence possible and increased cases reported to the police and Social Welfare Officers.

It is recommended that to sustain the results achieved, the following need to be done, more and consistent awareness-raising campaigns to parents, community and children on sexual violence to address attitudes and perceptions towards children need to be carried out.

In addition, CBCPM's work should be strengthened to ensure that its work produces tangible and sustainable outcomes in combating sexual violence against children. It is also important to invest in CBCPMs because these are easily accessible and can provide quick response and prevention services to children at risk or victims of sexual violence.

\section{Acknowledgements}

Our special thanks to Prof. Heidi Stoeckl and Isabelle Pearson of the London School of Hygiene and Tropical Medicine (LSHTM), Dr. Samuel Likindikoki of the Muhimbili University of Health and Allied Sciences (MUHAS), Dr. Gerry Mshana and Dr. Joyce Wamoyi of National Institute for Medical Research (NIMR) for facilitating the British Academic Writing Workshop and VAWC Satellite Sessions. We also extend our gratitude to Rombo District Council for granting permission for data collection and our special thanks to all the research assistants, Upendo Ramadhani, Gift Muro and Novatus Njaala.

\section{Conflicts of Interest}

The authors declare no conflicts of interest regarding the publication of this paper.

\section{References}

Borgatti, S. P., \& Ofem, B. (2010). Overview: Social Network Theory and Analysis. In A. J. Daly (Ed.), Social Network Theory and Educational Change (pp. 17-29). Harvard Education Press.

Bronfenbrenner, U. (1978). Bronfenbrenner's Ecological Model of Child Development, Some Principles of the Ecology of Child Development from the Work Bronfenbrenner. Harvard University Press.

Cerna-Turoff, I., Fang, Z., Meierkord, A., Wu, Z., Yanguela, J., Bangirana, C. A., \& Meinck, F. (2021). Factors Associated with Violence against Children in Low-and Mid- 
dle-Income Countries: A Systematic Review and Meta-Regression of Nationally Representative Data. Trauma, Violence, \& Abuse, 22, 219-232. https://doi.org/10.1177/1524838020985532

Chilwalo, M. (2020). Community-Based, Endogenous and Ubuntu Inspired Child Protection Mechanisms: Case of the Girl Power Program in Addressing School-Related Gender-Based Violence in Chibombo District of Zambia. African Journal of Social Work, 10, 10-15.

Collins, O. O. (2020). Violence against Children with Special Needs: Types, Causes and Health Consequences. International Journal of Health and Pharmaceutical Research, 5, $1-6$.

CPWG (Child Protection Working Group) (2012). Working with Community-Based Child Protection Committees and Network. Child Protection Working Group.

Creswell, J. W. (2009). Research Design. Qualitative, Quantitative and Mixed Methods Approaches (3rd ed.). Sage.

Development Links Consult (2016). The Handbook for Case Management in Child Protection. Development Links Consult.

Eneh, J., Nnama-Okechukwu, C. U., \& Uzuegbu, C. (2018). Social Work with Families. In U. O. Okoye, N. Chukwu, \& P. Agwu (Eds.), Social Work in Nigeria: Book of Readings. University of Nigeria Press Ltd.

Ezekiel, M., Idda, M., Felix, K., Rose, M., Amani, A., Switbert, K., \& Eustace, M. (2017). Factors Associated with Child Sexual Abuse in Tanzania: A Qualitative Study. Tanzania Journal of Health Research, 19, 1-10. https://doi.org/10.4314/thrb.v19i2.9

Fazzi, L. (2019). Social Workers' Views on Community Involvement in Child Protection Work in Italy. Child \& Family Social Work, 24, 1-8. https://doi.org/10.1111/cfs.12472

Gillieatt, S., Fernandes, C., Fielding, A., Hendrick, A., Martin, R., \& Matthews, S. (2015). Social Network Analysis and Social Work Inquiry. Australian Social Work, 68, 338-351. https://doi.org/10.1080/0312407X.2015.1035660

Gwanyemba, J. K., Kiwia, R. H., \& Zuberi, B. G. (2016). The Effectiveness of Formal and Informal Community-Based Child Protection Mechanisms in Rural Areas of Tanzania: Evidences from Selected World Vision Tanzania Projects. Developing Country Studies, $6,43-47$.

ICPREC (International Child Protection Rights and Evaluation Consultants) (2012) Lessons for Protection: A Comparative Analysis of Community-Based Child Protection Mechanisms Support by Plan in Asia. International Child Protection Rights and Evaluation Consultants.

Ireri, A. W. (2018). An Assessment of the Role of Community-Based Child Protection Mechanisms in Kilifi County, Kenya (Thesis). Strathmore University. http://suplus.strathmore.edu/handle/11071/6046.

Kisanga, F. (2012). Child Sexual Abuse in Urban Tanzania: Possibilities and Barriers for Prevention. Doctoral Dissertation, Umeå universitet.

Kostelny, K., Wessells, M., \& Ondoro, K. (2014). Community-Based Child Protection Mechanisms in Kilifi, Kenya: A Rapid Ethnographic Study in Two Rural Sites. Interagency Learning Initiative on Community-Based Child Protection Mechanisms and Child Protection Systems.

Kostelny, K., Wessells, M., \& Ondoro, K. (2020). Enabling Full Participation: A Community-Led Approach to Child Protection. In N. Balvin, \& D. Christie (Eds.), Children and Peace (pp. 291-305). Springer. https://doi.org/10.1007/978-3-030-22176-8_18

LHRC (Legal and Human Rights Centre) (2018). Human Rights Report in Tanzania. Le- 
gal and Human Rights Centre.

LHRC (Legal and Human Rights Centre) (2020). Summary of Human Rights Report. Legal and Human Rights Centre.

Ligiero, D., Hart, C., Fulu, E., Thomas, A., \& Radford, L. (2019). What Works to Prevent Sexual Violence Against Children. https://www.togetherforgirls.org/svsolutions

O'Leary, P., Hutchinson, A., \& Squire, J. (2015). Community-Based Child Protection with Palestinian Refugees in South Lebanon: Engendering Hope and Safety. International Social Work, 58, 717-731. https://doi.org/10.1177/0020872815584427

Plan International (2015). Strengthening Community-based Mechanisms and State Systems on Child Protection Systems, A POLT Global Initiatives. Plan International.

Plan International (2016). Community-Based Child Protection Mechanism: Global Synthesis Report. Plan International.

Plan International (2017). Community-Based Child Protection as a Strategy for Protecting South Sudanese Refugee Children: A Case Study from Gambella, Ethiopia. Plan International.

Prickett, I., Moya, I., Muhorakeye, L., Canavera, M., \& Stark, L. (2013). Community-Based Child Protection Mechanisms in Refugee Camps in Rwanda: An Ethnographic Study. Child Protection in Crisis-Network for Research, Learning \& Action.

Reuben, M., Mohamed, F., \& Mutasa, F. (2021) Strategies for Preventing and Responding to Sexual Violence against Children in Rombo District, Tanzania: A Mixed Method Study. Open Journal of Social Sciences, 9, 439-453.

https://doi.org/10.4236/jss.2021.99032

Save the Children Norway (2012). Guide to Community Based Child Protection. The Village Safety Net Programme in Cambodia.

Stark, L. (2013). Community-based Child Protection Mechanisms among Urban Refugees in Kampala, Uganda. An Ethnographic Study.

Together for Girls (2018). Accelerating Action to Address Violence against Women and Children: Key Lessons from the Together from Girls Partnership in Tanzania. Together for Girls.

UNICEF (United Nations Children's Fund) Tanzania, Division of Violence Prevention, National Center for Injury Prevention and Control, Centres for Disease Control and Prevention, \& Muhimbili University of Health and Allied Sciences (2011). Violence against Children in Tanzania: Findings from a National Survey, 2009. United Nations Children's Fund.

URT (United Republic of Tanzania) (2009). The Law of Child Act No. 21 of 2009.

URT (United Republic of Tanzania) (2015). The Law of Child Act Child Protection Regulation.

URT (United Republic of Tanzania) (2016). The National Plan of Action to Address Violence against Women and Children.

War Child, UK (2010). Strengthening Community-Based Child Protection Mechanisms in Uganda and the Democratic Republic of Congo. War Child, UK.

Wessells, M. G. (2015). Bottom-Up Approaches to Strengthening Child Protection Systems: Placing Children, Families, and Communities at the Center. Child Abuse and Neglect, 43, 8-21. https://doi.org/10.1016/j.chiabu.2015.04.006

Wessells, M. G. (2016). Strengths-Based Community Action as a Source of Resilience for Children Affected by Armed Conflict. Global Mental Health, 3, E1.

https://doi.org/10.1017/gmh.2015.23 
Wessells, M., Kostelny, K., \& Ondoro, K. (2014). A Grounded View of Commnity-Based Child Protection Mechanism and Their Linkages with the Wider Child Protection System in the Rural and Urban Area in Kenya. Interagency Learning Initiative on Community-Based Child Protection Mechanisms and Child Protection Systems.

Wu, C. (2020, September). Development Path Construction of the Community-Based Child Protection. In The 3rd International Conference on Economy, Management and Entrepreneurship (ICOEME 2020) (pp. 199-203). Atlantis Press.

https://doi.org/10.2991/aebmr.k.200908.032 